Original Research

\title{
How Potassium Content in Soil Shapes Giant Panda Distribution
}

\author{
Dan Zhao',2, Juan Wang ${ }^{2}$, Wende Chen' ${ }^{2}$ Xian'an Liu ${ }^{1,2}$, \\ Chao Zhang ${ }^{3,4}$, Peihao Peng ${ }^{1,2 *}$ \\ ${ }^{1}$ College of Earth Sciences, Chengdu University of Technology, Chengdu, China \\ ${ }^{2}$ Institute of Ecological Resources and Landscape Architecture, Chengdu University of Technology, Chengdu, China \\ ${ }^{3}$ School of Geographic and Environmental, Shandong Normal University, Jinan, China \\ ${ }^{4}$ Shandong Agriculture and Engineering University, Jinan, China
}

Received: 12 November 2017

Accepted: 2 January 2018

\begin{abstract}
Potassium (K), one of main essential macronutrient elements in soil, is vital to the growth and metabolism of giant pandas (Ailuropoda melanoleuca) and its staple food bamboos (SFB). However, it is still unknown how the content of $\mathrm{K}$ in soil shapes giant panda distribution. To address this problem, we use geographical information system (GIS) and regression analysis to measure their spatial distribution data and analyze their relationships. Our results show a unimodal relationship between the species richness of SFB and $\mathrm{K}\left(\mathrm{R}^{2}=0.90, P<0.01\right)$, a significant positive linear correlation relationship between SFB and giant panda $\left(\mathrm{R}^{2}=0.47, P<0.01\right)$, and a significant unimodal relationship between the $\mathrm{K}$ and giant panda $\left(\mathrm{R}^{2}=0.58, P<0.01\right)$. Moreover, results reveal that the giant panda may tend to select habitats with $\mathrm{K}$ in the soil ranging from 2.58 to $3.14(\mathrm{mg} / \mathrm{g})$. Our study also highlights the important effect of the eco-geological environment in shaping the distribution of giant panda. Our study suggests that it is essential to incorporate the beneficial and harmful element factors of an eco-geological environment into wildlife habitat research and management. It should improve on habitat estimation, corridor establishment, and biodiversity conservation.
\end{abstract}

Keywords: potassium, giant panda, staple food bamboos, spatial distribution, eco-geological environment, geographical information system (GIS), regression analysis

\section{Introduction}

Giant panda (Ailuropoda melanoleuca), as one global flagship of threatened species for priority conservation, lives in the mountains of west-central China, although is one member of the Carnivora, extremely specializes

*e-mail: peihaop@163.com in feeding on bamboo, which makes up more than $99 \%$ of their diet [1-3]. Because of the effective efforts to conserve it, its habitat has been exhibited and its state was recently downgraded from "endangered" to "vulnerable" by the IUCN [4]. The spatial distribution of staple food bamboos (SFB) for giant panda is vital to population stability and habitat suitability [5-7]. With increases in climate change and human disturbances, the threats to habitats of panda are very insensitive [8-14]. However, we 
still have very limited knowledge of how environmental factors and underlying mechanisms determine the distribution of panda, even though we have known the distribution of panda is related to the distribution of SFB. Understanding their mechanisms of habitat selection could help to protect this important species under serious threats of global change. Species always select their relatively suitable habitats based on their life strategy [15, 16]. Previous studies have proposed that the richness and quality of understory bamboo were associated with the spatial distribution and survival of panda [6, 17]. Besides the distribution of bamboo, forest type, terrain slope, and elevation were also used to identify potential habitats for panda [18].

As previous studies have proposed, the contents of some specific elements in soil could influence the distribution of species and subsequently influence the diversity of distribution patterns [16, 19, 20]. Moreover, previous studies on foraging strategies of giant panda have shown that the nutritional quality of food resources for it is more important than their quantity, because of maximized sufficiency of intake, which greatly influences the habitat selection for panda [2, 3]. Potassium $(\mathrm{K})$, one of the three main essential macronutrients in the soil, plays a key role in plant growth and metabolism and its availability in soil affects plant inter-specific competition and interaction of plant-microorganisms [21-25].

However, we have very limited knowledge on how the content of $\mathrm{K}$ in soil shapes giant panda distribution. It is essential to find the potential relationships of spatial distribution between $\mathrm{K}$, giant panda, and SFB. To address this issue, we used GIS and regression analysis to measure their spatial distribution data and analyze their relationships in Sichuan Province - the main reserve of panda in China.

\section{Material and Methods}

\section{Study Area}

The study area encompasses the entire 32 nature reserves for giant panda, which occupy a total area of about $17040 \mathrm{~km}^{2}$ in Sichuan Province, the southwestern region of China, and the edge of the Tibetan Plateau $\left(101^{\circ} 25^{\circ}-105^{\circ} 24^{\circ} \mathrm{E} ; 28^{\circ} 7^{\prime}-33^{\circ} 21^{\prime} \mathrm{N}\right)$ (Fig. 1). According to the field surveys, there are approximately 693 individuals living here, accounting for $57.46 \%$ of the estimated number of pandas distributed in Sichuan Province, or $43.42 \%$ of the total wild individuals [26]. There are 28 species in 7 general of SFB (include the variant species)

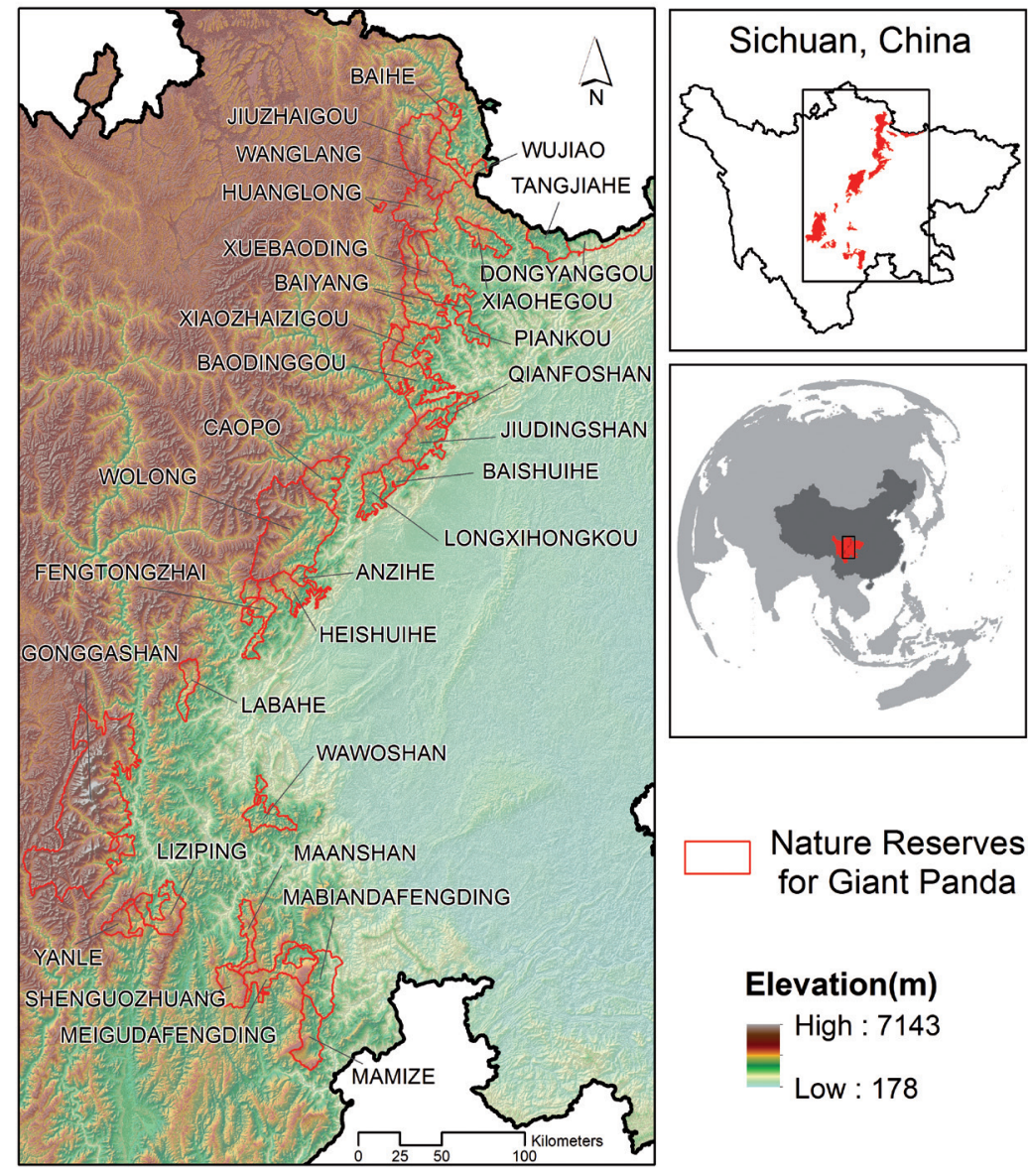

Fig. 1. 32 nature reserves for giant panda are located in Sichuan Province, the southwestern region of China, and the edge of the Tibetan Plateau. 


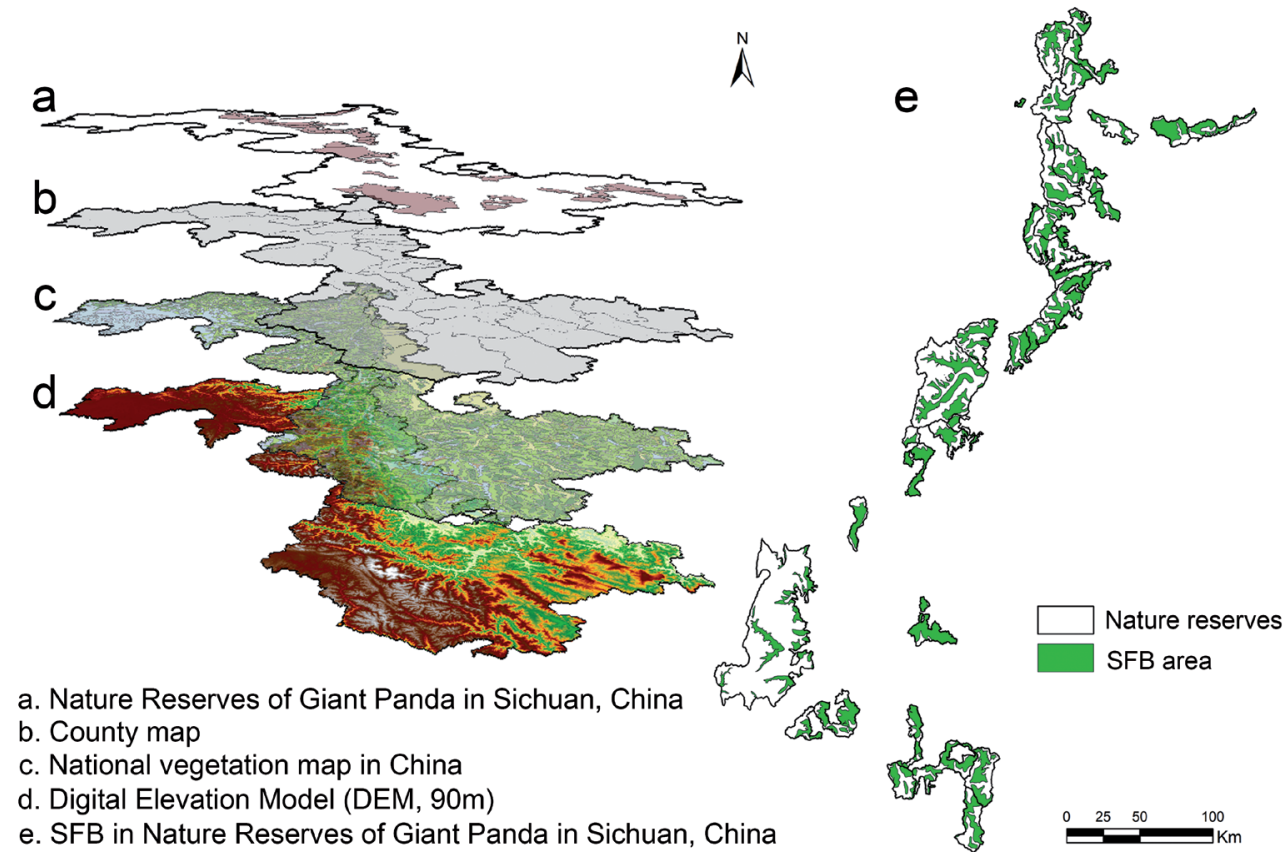

Fig. 2. There are 28 species in 7 general of SFB (include the variant species) distributed in nature reserves for giant panda in Sichuan Province.

distributed under the canopy of the forest in relatively steep mountains with elevations ranging from $700 \mathrm{~m}$ to $3500 \mathrm{~m}[26,27]$.

\section{Staple Food Bamboos (SFB) for Giant Panda}

To map the distribution of SFB in the nature reserves for giant panda, we extracted and overlaid all SFB data of reserves, county, vegetation, and elevation in the ArcGIS version 10.4 (ESRI, Redlands, USA) (Fig. 2). First, we extracted the vegetation data, which included deciduous forests, broad-leaved forests, and mixed forests from the national vegetation map in China (Zhang et al., 2007). Then we derived the elevation data where the SFB distribute as recorded from the survey report [26] by the digital elevation model (DEM) at $90 \mathrm{~m}$ spatial resolution [28]. Last, we mapped the species richness of SFB in the nature reserves, merging the data of every SFB (Fig. 2).

\section{Giant Panda}

We also used the Arcgis tool to calculate and map the density of panda for each reserve using the ratio of the number of panda distributed in the reserve [26] to the SFB area of the reserve (Fig. 3a).

The reserves with relatively high density of panda are Baiyang, Xioahegou, Wanglang, Xiaozhaizigou, and Wolong (Fig. 3a).

\section{Potassium (K)}

The contents of potassium ( $\mathrm{K}$, representing $\mathrm{K}_{2} \mathrm{O}$ ) were extracted from the Regional Geochemistry-National
Reconnaissance Program (RGNR) and the National Multi-Purpose Regional Geochemical Survey Project (NMPRGS) at a 1:500,000 spatial scale resolution. According to the hierarchical system of the project, 18 classes of $\mathrm{K}$ contents in the soil were identified in the research area. In the Arcgis environment, we used a tabulate area tool to overlay the distribution maps of SFB, the density of panda, and the $\mathrm{K}$ contents in the soil, and to calculate the richness of SFB and the density of panda for each $\mathrm{K}$ intervals. The spatial distribution of $\mathrm{K}$ shows that Xiaozhaizigou, Baiyang, Baodinggou, Piankou, and Liziping nature reserves have high $\mathrm{K}$ contents in the soil (Fig. 3b).

\section{Statistical Analyses}

We regressed the density of panda against species richness of edible bamboo and contents of $\mathrm{K}$ in soil to detect the relationships between them. Also, to take account of their potential non-linear relationships we used quadratic regressions. Among these three variables, three relationships were tested, i.e., the relationship of $\mathrm{K}$-species richness of SFB, the relationship of K-density of panda, and the relationship of the density of panda and species richness of SFB. We performed the regression analyses in IBM SPSS on Windows, version 21 (SPSS Inc., Chicago, IL, USA).

\section{Results and Discussion}

We found that species richness of SFB shows a unimodal relationship with the content of $\mathrm{K}$ in the soil $\left(\mathrm{R}^{2}=0.90, P<0.01\right)$. For $\mathrm{K}<2.5(\mathrm{mg} / \mathrm{g})$, there is a positive 

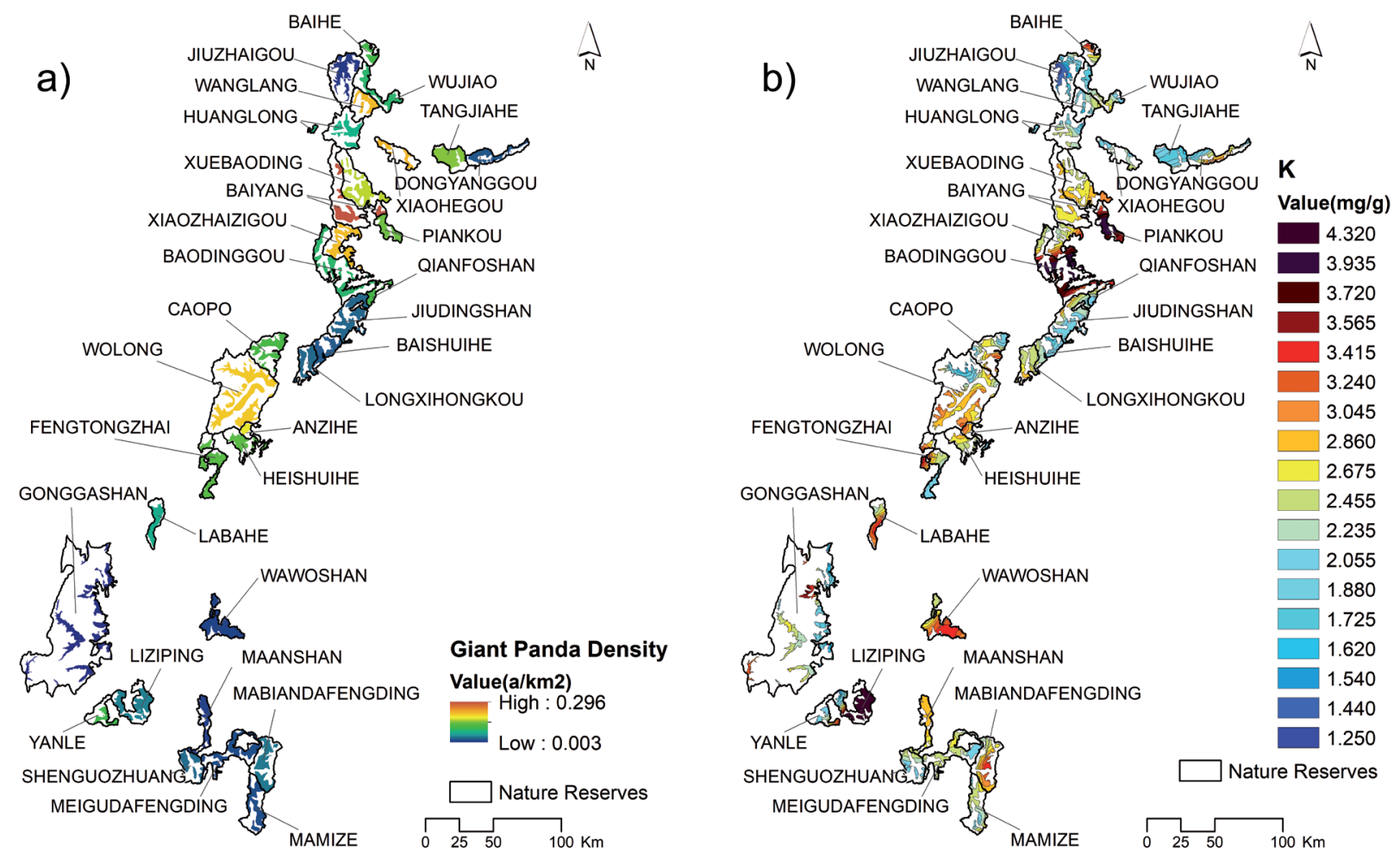

Fig. 3. Spatial distribution of a) the density of giant panda $\left(\mathrm{a} / \mathrm{km}^{2}\right)$ and $\left.\mathrm{b}\right)$ the contents of $\mathrm{K}(\mathrm{mg} / \mathrm{g})$ in soils at the area of SFB (staple food bamboos for giant panda) in nature reserves for giant panda in Sichuan Province.

relationship between species of SFB and $\mathrm{K}$; then after the point, it regresses into a negative relationship (Fig. 4a).

We also found a significant positive linear relationship between species of SFB and the density of panda. ( $\mathrm{R}^{2}=0.43, P<0.01$; Fig. $\left.4 \mathrm{~b}\right)$.

The relationship between $\mathrm{K}$ and panda is clearly unimodal $\left(\mathrm{R}^{2}=0.58, \mathrm{p}<0.01\right.$, Fig. $\left.4 \mathrm{c}\right)$. According to the prediction function for the density of panda, the areas with $\mathrm{K}$ values around 3 (mg/g) have highest densities.

\section{Potassium (K)-Staple Food Bamboos (SFB) Relationship}

As a major and essential plant macronutrient and the most abundantly absorbed cation in higher plants, $\mathrm{K}$ contributes greatly to the survival of plants [24, 29]. For example, this element is involved in osmotic balance and photosynthesis $[23,30]$. Our results indicate a significant unimodal relationship between species richness of bamboo and the content of $\mathrm{K}$ in soils (Fig. 4a). However, the $\mathrm{K}$ concentration implies a key role in shaping the distribution of bamboo. This matches with previous studies proposed that $\mathrm{K}$ plays a particularly critical role in plant growth and metabolism [30, 31]. It also has been shown that crop quality would be improved by increasing plant metabolism [29]. Without an adequate amount of available $\mathrm{K}$, it is concluded that SFB, as one of the higher plants, might develop poor roots, grow slowly, produce smaller seeds, and subsequently have lower yields. To the unimodal relationship between the species richness of SFB and the K contents, we may still need to know the mechanism of the limits of $\mathrm{K}$ in shaping the distribution of those bamboo species in this area. The results reveal that the areas with $\mathrm{K}$ value around $2.5-3(\mathrm{mg} / \mathrm{g})$ would be the most suitable intervals for the distribution of bamboo species (Fig. 4a). Our results also provide a new insight into an environmental assessment and finding a new potential stable food bamboo habitat. Furthermore, it has been known that $\mathrm{K}$ fertilizer is a key factor in formatting crop production and increasing its quality [16]. Our results indicate that, in order to increase the diversity of SFB, we could apply $\mathrm{K}$ fertilizer into the soil under some values of $\mathrm{K}$ contents. Meanwhile, with SFB diversity at an increased risk in this area, under climate change about half of the SFB species may potentially colonize new climatically suitable areas under universal dispersal [13]. However, it can help to get more potential suitable habitats for the SFB if we can make appropriate management strategies via changing the $\mathrm{K}$ contents in some specific areas.

\section{Staple Food Bamboos (SFB) and Giant Panda Relationship}

According to the assessment of the impacts of climate change on bamboo forests and their alpha and beta diversities in the giant panda habitats and reserves, climate change-induced decline in bamboo habitats and species diversity would be a big challenge to the food availability of panda in the future [14, 32]. Because of the food specialization for panda, the availability of 

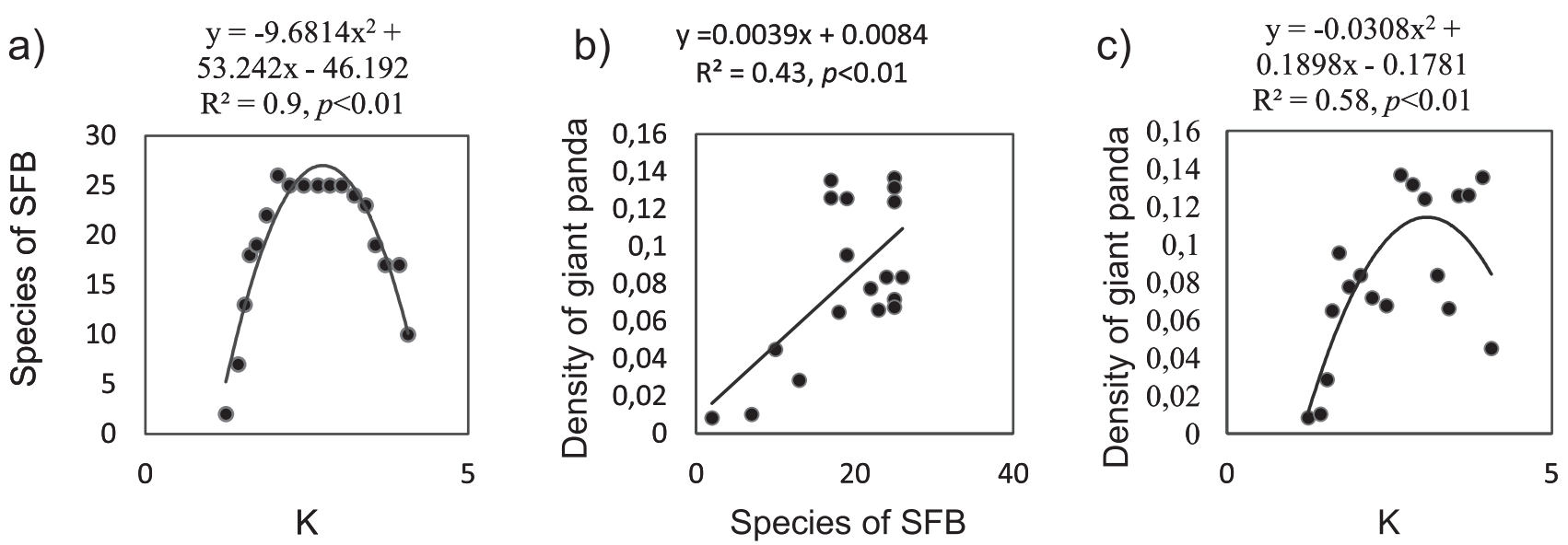

Fig. 4. Results of relationships: a) between $\mathrm{K}$ and species of SFB (staple food bamboos for giant panda), b) between SFB and density of giant panda, and c) between $\mathrm{K}$ and density of giant panda.

SFB is the most important factor for its survival [3]. To our knowledge, the results for the first time showed a significant positive relationship between the density of panda and the diversity of the SFB in the research area (Fig. 4b). Two possible mechanisms potentially exist to explain the relationship. Firstly, the higher diversity of the SFB could provide more food selection for the panda individuals, even if it is so specialized [18, 27]. Secondly, the higher diversity of the SFB may contribute more to the local diversity of vegetation, and the higher ecosystem diversity probably provides more stable and suitable habitats for panda [33] because diversity is so critical to the stability of the environments $[33,34]$. The findings could be also useful in further habitat protection strategies for panda.

\section{Potassium (K)-Giant Panda Relationship}

Exploring the relationship between animals and their habitats is a central goal in wildlife ecology [15, 18, 35]. Besides bamboo-related factors, slope, elevation, and solar radiation were considered main factors for panda selecting their suitable habitats [18]. But we still have very limited knowledge on how the geological background of the nutrient element affects the distribution of panda. Our results showed that $\mathrm{K}$ content of the soil could significantly affect the distribution of panda. Several underlying mechanisms could explain the results we presented here. In previous studies, increases in the leaf $\mathrm{K}$ concentration could increase the feeding rate of herbivores [36]. Additionally, nutrient additions (N, P, $\mathrm{K}$ ) could increase the $\mathrm{N}$ content in the leaves, making the leaves more favorable for predator feeding [36]. More interestingly, our study found that the nutrient element, $\mathrm{K}$, shapes the distribution of panda by unimodal pattern (Fig. 4c). That relationship is, to some extent, similar to the statement of Liebig's law of the minimum: that plant growth is regulated by the nutrients supplied [22, 37]. It also may indicate that the high content of $\mathrm{K}$ in the soil may also have negative effects on the distribution of panda. Excess $\mathrm{K}$ in the soil is harmful to their habitat possibly because of the toxicological effects or reducing other cations the wildlife can take up [22, 38]. It should be recognized that the maximum density of giant panda is at a concentration of $\mathrm{K}$ in the soil ranging from 2.58 to $3.14(\mathrm{mg} / \mathrm{g})$, which is the same intervals for the areas with the highest diversity of bamboo species. This may imply that the giant panda might have a higher tolerance of $\mathrm{K}$ content in the soil than the bamboos do, which should be paid more attention in future studies.

\section{Conclusions}

In this study we used GIS and regression analysis to measure the spatial distribution data and analyze relationships of the giant panda, SFB, and K. Our results show a unimodal relationship between species richness of SFB and $\mathrm{K}\left(\mathrm{R}^{2}=0.90, P<0.01\right)$, a significant positive linear correlation relationship between $\mathrm{SFB}$ and giant panda $\left(\mathrm{R}^{2}=0.47, P<0.01\right)$, and a significant unimodal relationship between $\mathrm{K}$ and giant panda $\left(\mathrm{R}^{2}=0.58\right.$, $P<0.01$ ), respectively. Moreover, results reveal that the giant panda may tend to select the habitats with $\mathrm{K}$ in the soil ranging from 2.58 to $3.14(\mathrm{mg} / \mathrm{g})$. Our study also highlights the important effect of the eco-geological environment in shaping the distribution of giant panda. Our study suggests that it is essential to incorporate the beneficial and harmful element factors of ecogeological environment into wildlife habitat research and management. It should improve on the future planning of habitat estimation, corridor establishment, and biodiversity conservation.

\section{Acknowledgements}

We thank Prof. Wenge Ni-Meister and Dr. Lingfeng Mao for thoughtful discussion. We also thank anonymous reviewers and editors for their valuable 
comments on the manuscript. We gratefully acknowledge financial support from the National Natural Science Foundation of China (grant No. 41671432), the State-Sponsored Scholarship Program of the Chinese Scholarship Council (grant No. 201508515006), and the Key Teachers Cultivation Plan Fund of Chengdu University of Technology (grant No. 10912JXGG201535).

\section{Conflict of Interest}

The authors declare no conflict of interest

\section{References}

1. DIERENFELD E.S., HINTZ H.F., ROBERTSON J.B., VAN SOEST P.J., OFTEDAL O.T. Utilization of bamboo by the giant panda. J Nutr, 112 (4), 636, 1982.

2. SCHALLER G.B. Giant pandas of Wolong; University of Chicago press: Chicago, 1985.

3. WEI W., NIE Y., ZHANG Z., HU Y., YAN L., QI D., LI X., WEI F. Hunting bamboo: Foraging patch selection and utilization by giant pandas and implications for conservation. Biological Conservation, 186, 260, 2015.

4. SWAISGOOD R., WANG D., WEI F. Ailuropoda melanoleuca: the IUCN red list of threatened species. International Union for Conservation of Nature. e. T712A45033386. http://www. iucnredlist. org/details/712/0, 2016.

5. REID D.G., JINCHU H., SAI D., WEI W., YAN H. Giant panda Ailuropoda melanoleuca behaviour and carrying capacity following a bamboo die-off. Biological Conservation, 49 (2), 85, 1989.

6. LINDERMAN M., BEARER S., AN L., TAN Y., OUYANG Z., LIU J. The effects of understory bamboo on broad-scale estimates of giant panda habitat. Biological Conservation, 121 (3), 383, 2005.

7. WEI F., HU Y., YAN L., NIE Y., WU Q., ZHANG Z. Giant pandas are not an evolutionary cul-de-sac: evidence from multidisciplinary research. Molecular biology and evolution, 32 (1), 4, 2014.

8. LOUCKS C.J., LU Z., DINERSTEIN E., WANG H., OLSON D.M., ZHU C., WANG D. Ecology. Giant pandas in a changing landscape. Science, 294 (5546), 1465, 2001.

9. BYSTRIAKOVA N., KAPOS V. Bamboo diversity: the need for a Red List review. Biodiversity, 6 (4), 12, 2006.

10. TUANMU M.-N., VIÑA A., WINKLER J.A., LI Y., XU W., OUYANG Z., LIU J. Climate-change impacts on understorey bamboo species and giant pandas in China's Qinling Mountains. Nature Climate Change, 3 (3), 249, 2012.

11. MORI A.S., FURUKAWA T., SASAKI T. Response diversity determines the resilience of ecosystems to environmental change. Biol Rev Camb Philos Soc, 88 (2), 349, 2013.

12. LIU J., VIÑA A. Pandas, Plants, and People 1, 2. Annals of the Missouri Botanical Garden, 100 (1-2), 108, 2014.

13. LI R., XU M., WONG M.H.G., QIU S., SHENG Q., LI X., SONG Z., THUILLER W. Climate change-induced decline in bamboo habitats and species diversity: implications for giant panda conservation. Diversity and Distributions, 21 (4), 379, 2015

14. LI R., XU M., WONG M.H.G., QIU S., LI X., EHRENFELD D., LI D. Climate change threatens giant panda protection in the $21^{\text {st }}$ century. Biological Conservation, 182, 93, 2015.

15. MORRISON M.L., MARCOT B., MANNAN W. Wildlifehabitat relationships: concepts and applications; Island Press: Washington, D.C., 2012.

16. ZÖRB C., SENBAYRAM M., PEITER E. Potassium in agriculture - status and perspectives. Journal of plant physiology, 171 (9), 656, 2014

17. ZHANG Z., SWAISGOOD R.R., ZHANG S., NORDSTROM L.A., WANG H., GU X., HU J., WEI F. Old-growth forest is what giant pandas really need. Biol Lett, 7 (3), 403, 2011.

18. HULL V., ZHANG J., HUANG J., ZHOU S., VINA A., SHORTRIDGE A., LI R., LIU D., XU W., OUYANG Z., ZHANG H., LIU J. Habitat Use and Selection by Giant Pandas. PLoS One, 11 (9), e0162266, 2016.

19. TILMAN D., KILHAM S.S., KILHAM P. Phytoplankton community ecology: the role of limiting nutrients. Annual Review of Ecology and Systematics, 13, 349, 1982.

20. WANG J. Study on the Relation between Geological Background and Plant Diversity of Gongbu Nature Reserve in Tibet [Doctor Thesis]: Chengdu University of Technology; 2013.

21. MARSCHNER P. Marschner's mineral nutrition of higher plants, 3RD ed.; Academic press: London, 2012.

22. RUSSELL E.J. A student's book on soils and manures; Cambridge University Press: London, 2013.

23. WANG Y., WU W.-H. Potassium transport and signaling in higher plants. Annual Review of Plant Biology, 64, 451, 2013.

24. SARDANS J., PEÑUELAS J. Potassium: a neglected nutrient in global change. Global Ecology and Biogeography, 24 (3), 261, 2015.

25. BARKER A.V., PILBEAM D.J. Handbook of plant nutrition; CRC press: Boca Raton, 2015.

26. State Forestry Administration. The $3^{\text {rd }}$ National Survey report on giant pandas in China; Science Press: Beijing, 2006.

27. TAYLOR A.H., ZISHENG Q. Structure and dynamics of bamboos in the Wolong Natural Reserve, China. American journal of botany, 80, 375, 1993.

28. JARVIS A., REUTER H.I., NELSON A., GUEVARA E. Hole-filled SRTM for the globe Version 4. available from the CGIAR-CSI SRTM 90 m Database (http://srtm. csi. cgiar. org), 2008

29. SINDHU S.S., PARMAR P., PHOUR M. Nutrient cycling: potassium solubilization by microorganisms and improvement of crop growth; Springer-Wien: New York, 2012.

30. HU W., COOMER T.D., LOKA D.A., OOSTERHUIS D.M., ZHOU Z. Potassium deficiency affects the carbonnitrogen balance in cotton leaves. Plant Physiology and Biochemistry, 115, 408, 2017.

31. MANNING D.A. Mineral sources of potassium for plant nutrition. A review. Agronomy for sustainable development, 30 (2), 281, 2010.

32. WANG M., ZHENG Q., SHEN Q., GUO S. The critical role of potassium in plant stress response. Int J Mol Sci, 14 (4), 7370, 2013.

33. VIÑA A., LIU J. Hidden roles of protected areas in the conservation of biodiversity and ecosystem services. Ecosphere, 8 (6), e01864, 2017. 
34. TILMAN D., REICH P.B., KNOPS J.M. Biodiversity and ecosystem stability in a decade-long grassland experiment. Nature, 441 (7093), 629, 2006.

35. TELLERÍA J.L. Wildlife habitat requirements: concepts and research approaches. Current Trends in Wildlife Research; In: R. M, B. A, J. G, editors, Springer, Cham: Switzerland, 1, 79, 2016.

36. SANTIAGO L.S., WRIGHT S.J., HARMS K.E., YAVITT J.B., KORINE C., GARCIA M.N., TURNER B.L. Tropical tree seedling growth responses to nitrogen, phosphorus and potassium addition. Journal of Ecology, 100 (2), 309, 2012.

37. WEIL R.R., BRADY N.C., WEIL R.R. The nature and properties of soils, $15^{\text {th }}$ ed.; Pearson: Columbus, 2016.

38. MAO Q., LU X., CHEN H., MO J. Responses of terrestrial plant diversity to elevated mineral element inputs. Acta Ecologica Sinica, 35 (17), 5884, 2015. 
